\title{
Analysis of biogeochemical processes in plastic-covered soil during establishment period in strawberry cultivation
}

\author{
M. Meyer ${ }^{1}$ (D) D. Diehl ${ }^{1} \cdot$ G. E. Schaumann ${ }^{1} \cdot$ K. Muñoz ${ }^{1}$
}

Received: 2 April 2020 / Accepted: 16 September 2020 / Published online: 30 September 2020

(c) The Author(s) 2020 OPEN

\begin{abstract}
Plastic mulching (PM) has become a widely applied agricultural practice to optimize plant growth. However, it is still under debate how PM influences biogeochemical soil processes and thus important factors of soil quality, such as soil organic matter (SOM) composition, aggregate stability and microbial biomass. Our objective was to identify the impact of PM on biogeochemical soil processes. Therefore, we compared a plastic-covered strawberry cultivation system (PC) with an uncovered system (NC) in three soil layers $(0-10,10-30$ and $30-60 \mathrm{~cm})$ at three dates during a 4-month period of strawberry establishment from their transplanting in summer to the beginning of winter. The PC shifted the microclimate of the soil towards higher temperatures but lower moistures in the $0-35 \mathrm{~cm}$ soil layer compared to uncovered soil. Predominantly in the surface layer, the PC reduces leaching processes, which can improve nutrient (fertilizer) use efficiency. PC increased SOM and shifted SOM to a more stable SOM. The higher SOM under PC despite larger microbial biomass and elevated temperatures, indicate that belowground biomass inputs compensate the potential SOM losses by an enhanced SOM decomposition under PC. We demonstrated that PC influenced soil processes already within the 4-month period of strawberry establishment, partially down to the 30-60 soil layer. Further, long-term studies are required to estimate the influence of multi-annual PM application on biogeochemical soil processes and on soil quality.
\end{abstract}

Keywords Plastic mulching · Strawberry cultivation · Soil aggregates · Soil organic matter · Soil microbial biomass

$\begin{array}{llll}\text { Abbreviations } & \text { BD } & \text { Bulk density } \\ \text { PM } & \text { Plastic mulching } & \text { WSA } & \text { Water-stable aggregates } \\ \text { SOM } & \text { Soil organic matter } & \text { MBC } & \text { Microbial biomass carbon } \\ \text { SOC } & \text { Soil organic carbon } & \text { MBN } & \text { Microbial biomass nitrogen } \\ \text { PC } & \text { Plastic-covered ridge-furrow system with } & \text { DOC } & \text { Dissolved organic carbon } \\ & \text { subsurface drip irrigation } & \text { C:N ratio } & \text { Carbon-to-nitrogen ratio } \\ \text { NC } & \text { Uncovered ridge-furrow system with subsur- } & \text { frSOM } & \text { Free soil organic matter } \\ & \text { face drip irrigation } & \text { OSOM } & \text { Aggregate occluded soil organic matter } \\ \text { CEC } & \text { Cation exchange capacity } & \text { aSOM } & \text { Mineral associated soil organic matter } \\ \text { ICP-OES } & \text { Inductively coupled plasma-optical emission } & \text { LFOM } & \text { Light fraction organic matter } \\ & \text { spectrometry } & \text { HFOM } & \text { Heavy fraction organic matter } \\ \text { EC } & \text { Electrical conductivity } & & \\ \text { TN } & \text { Total nitrogen } & & \end{array}$

Electronic supplementary material The online version of this article (https://doi.org/10.1007/s42452-020-03528-x) contains supplementary material, which is available to authorized users.

G. E. Schaumann, schaumann@uni-landau.de $\mid{ }^{1} \mathrm{i} E S$ Landau, Institute for Environmental Sciences, Group of Environmental and Soil Chemistry, University Koblenz-Landau, Landau, Germany.

SN Applied Sciences (2020) 2:1749 | https://doi.org/10.1007/s42452-020-03528-x 


\section{Introduction}

Plastic mulching (PM) has become a widely applied practice in agriculture [30]. By increasing soil temperature and reducing soil water evaporation PM can lead to higher yields, earlier harvests and improved product quality, which offers important economic benefits for farmers. Furthermore, PM can suppress weed growth and reduce fertilizer leaching, which in turn allows reducing herbicide and fertilizer application. In recent years, PM has also been associated with reduced soil organic matter (SOM) contents, entry of plastic waste and plasticizers into soil and shifts in microbial composition towards mycotoxigenic fungi (reviewed in Steinmetz et al. [58]). This has raised concerns regarding the sustainability of PM application, which is, particularly in Central Europe, increasingly used for out of season products, such as strawberries [42].

In strawberry cultivation in natural soil, strawberry plants are usually transplanted as seedlings into readily fertilized and drip-irrigated plastic-covered raised beds (ridge-furrow systems) during summer [42]. Plant development and establishment of the appropriate field structure, including tillage, fertilization, drip irrigation and building the ridge-furrow system can impact on various soil processes and parameters, such as aggregate formation, SOM decomposition and microbial biomass $[36,57]$. Additionally, the PM modify the soil microclimate and can influence hence various soil processes in the establishment phase of strawberries: For example, the soil temperature is elevated compared to uncovered areas [19], which can increase plant growth $[34,72]$ as well as microbial growth and activity $[5,29]$. This can increase root growth and root and microbial exudation, which might increase SOM stocks and promote microand macroaggregate formation [36]. On the other hand, an enhanced microbial activity and growth can promote SOM decomposition and thus nutrient release $[7,14]$. The impermeable plastic cover can alter soil moisture by impeding evaporation and rainfall infiltration $[26,38]$ and thus influence plant growth, microbial activity and growth $[7,57]$. Additionally, the impeded rainfall infiltration avoids excess water [38], which can reduce nutrient leaching [59] and aggregate breakdown caused by slaking and the mechanical impact of raindrops [36]. The PM impedes entry of aboveground biomass into soil and thus might reduce SOM stocks.

However, the partially inconsistent observations of PM influence on soil, reported e.g. for microbial biomass $[47,67]$, SOM $[41,51]$ and aggregate stability $[60,65]$, suggest that underlying processes are still not fully understood. Probably because the PM impact on biogeochemical processes also depend on season and soil depth, as the plastic-cover-induced changes in soil temperature and moisture decrease with soil depth $[15,22]$ and with season change from summer to lateautumn $[34,70]$. Additionally, PM is applied in various arrangements and periods and is often compared to other management systems, which differ not only in coverage but also in tillage, irrigation, fertilization and pesticide treatment $[39,41,48,74]$. Thus, to identify the effects of plastic coverage alone in various soil depths and during a seasonal course will help to understand which soil processes predominate under certain conditions and allow a better estimation of PM impact on soil quality.

Because of that, our objective was to investigate the soil processes under plastic coverage, influencing SOM quality, aggregate stability and microbial biomass during plant establishment period in strawberry cultivation. We compared a plastic-covered ridge-furrow system with subsurface drip irrigation (PC) to the same system without plastic coverage (NC) in three soil layers $(0-10,10-30$ and $30-60 \mathrm{~cm}$ ) at three dates within a 4-month period of strawberry establishment after field set-up and transplantation of seedlings. Our hypotheses were: (1) The PC increase the soil temperature and moisture in the establishment phase of strawberries but with declining degree with soil depth and season change from summer to late-autumn. (2) These shifts in the soils microclimate enhance plant and microbial growth and hence changes amount and composition of SOM towards larger contents of microbial biomass and SOM as well as larger carbon-to-nitrogen ratios (C:N ratios) due to SOM input. However, we also expect lower contents of dissolved organic carbon (DOC) and free SOM (frSOM) due to enhanced microbial activity. (3) Additionally, the impeded rainfall infiltration by PC reduces waterstable aggregate (WSA) breakdown and nutrient leaching, leading to higher WSA, aggregate occluded SOM (OSOM), nitrogen content and electrical conductivity $(E C)$ under PC. In order to investigate these hypotheses, we designed a semi-controlled field experiment that reflected current agricultural practice while enabling us to study soil processes in a homogeneous soil type and avoiding masking of treatments effects by landscape variation and edge effects.

\section{Material and methods}

\subsection{Site description}

The sampling site, a commercial strawberry field, is located near 'Offenbach an der Queich' in Southwestern Germany $\left(49^{\circ} 11^{\prime} \mathrm{N}, 8^{\circ} 10^{\prime} \mathrm{E}, 130 \mathrm{~m}\right.$ a.s.l.) in a temperate, humid 
climate with an annual average rainfall of $643 \mathrm{~mm} \mathrm{a}^{-1}$ (Weather station of Landau-Wollmesheim, Agrarmeteorologie Rheinland-Pfalz). Soil texture consisted of $7 \pm 2 \%$ sand, $83 \pm 5 \%$ silt and $10 \pm 3 \%$ clay in the $0-60 \mathrm{~cm}$ soil layer and was analyzed via hydrometer method [4]. The soil type was a silty loam (Anthrosol) according to FAO soil classification [24]. In April 2016, the field, cultivated with winter wheat in the previous season, was tilled and fertilized with $800 \mathrm{~kg} \mathrm{ha}^{-1}$ of an organic fertilizer, consisting mainly of barley malt culms and sugar beet components (MALTaflor $^{\circledast}$, Maltaflor Europa $\mathrm{GmbH}$, Andernach, Germany) and a mineral fertilizer ( $15 \mathrm{~kg} \mathrm{~N}, 5 \mathrm{~kg} \mathrm{P}, 30 \mathrm{~kg} \mathrm{~K}, 2 \mathrm{~kg} \mathrm{Mg})$. In lateJune 2016, a ridge-furrow system was established with subsurface drip irrigation and black plastic film covered ridges (Polyethylene, $50 \mu \mathrm{m}$ ) and bare furrows. In mid-July 2016, the strawberries (Fragaria x ananassa,'Malwina') were transplanted in double rows in the ridges with $40 \mathrm{~cm}$ distance between plants ( 8 plants per $\mathrm{m}^{2}$ ).

\subsection{Experimental design and soil sampling}

For the semi-controlled field experiment with the same soil type, crop type and agricultural treatment (apart from coverage type) a raster sampling was conducted in May 2016 to identify potential gradients and inhomogeneities of soil properties that may interfere with our experiment design (Table S1-S40, Online Resource).

For both treatments (PC and NC), we selected a treatment area $(21 \times 10 \mathrm{~m})$, consisting of five ridges (and furrows) aligned in north-south direction. In both treatment areas, five plots $(10 \times 1.5 \mathrm{~m})$ were randomly chosen for soil sampling: $P C(n=5)$ and NC $(n=5)$. Three soil samplings were conducted during the establishment phase of strawberries in 2016: 1 week after transplanting the strawberries on 25 July (T0) and two (T1) and four (T2) months later, respectively (on 26 September and 29 November).

During the sampling period, no manual weed control was necessary and no pesticides or fertilizers were applied. Subsurface drip irrigation (three emitters per meter) was applied identically in both treatment areas and took place from strawberry transplantation in July until mid-October. The field was irrigated depending on weather conditions for 3-4 $\mathrm{h}$, resulting in 7-11 $\mathrm{L}$ water per meter.

At each sampling date, a composite sample was taken in the ridges from three selected soil layers $(0-10,10-30$ and $30-60 \mathrm{~cm}$ ) in each of the randomly-selected plots in both treatment areas. Each composite soil sample consists of soil from five single cores. Beside the surface soil layer $(0-10 \mathrm{~cm})$, which was investigated in most former studies as the largest impact of PM was expected there (e.g. [47, 73]), we additionally included the root layer, which refers to the main root zone of the strawberries $(10-30 \mathrm{~cm})$, and the subsoil layer below the root zone $(30-60 \mathrm{~cm})$ to differentiate between potential depth-dependent PC impacts. The surface soil samples were collected with stainless steel soil sampling rings $(\mathrm{d}=5 \mathrm{~cm}, \mathrm{~h}=5 \mathrm{~cm})$, whereas the sub-surface soil samples $(>10 \mathrm{~cm})$ were collected with a boring rod. Composite soil samples were homogenized in a bucket, filled in labelled plastic bags and stored at $4{ }^{\circ} \mathrm{C}$ for further analyses.

All analyses with field-fresh soil were conducted directly after sampling. For all other analyses, the soil was either air-dried for 14 days at room temperature, sieved $(<2 \mathrm{~mm})$ and stored in plastic bags at room temperature or ovendried at $105^{\circ} \mathrm{C}$ for $24 \mathrm{~h}$, sieved $(<2 \mathrm{~mm}$ ) and milled (Planetary micro mill PULVERISETTE 7 premium line, Fritsch $\mathrm{GmbH}$, Idar-Oberstein, Germany) and stored in closed centrifuge tubes. All analyses with air- and oven-dried soil were performed within 2-4 months after sampling.

\subsection{Soil temperature and moisture}

Soil temperature and moisture were recorded hourly in both treatments by a measuring station (ecoTech ${ }^{\circledR}$, Bonn, Germany) at the soil depths 5, 15 and $35 \mathrm{~cm}$, according to the three soil layers selected for soil analysis. Therefore, one sensor was installed at each soil depth in both treatments (in total: six sensors). Air temperature and precipitation data were obtained from the weather station LandauWollmesheim (Agrarmeteorologie RLP).

\subsection{Soil characterization}

The cation exchange capacity (CEC) was determined according to DIN ISO 11260:1997-05. In brief, $3 \mathrm{~g}$ of fieldfresh soil were extracted three times with $0.1 \mathrm{M}$ barium chloride solution. After a washing step with $0.0025 \mathrm{M}$ barium chloride solution, the samples were extracted with $0.02 \mathrm{M}$ magnesia sulfate solution. Finally, the magnesia concentration was measured in the extract with inductively coupled plasma-optical emission spectrometry (ICP-OES) (Agilent 720 Series, Thermo Fisher Scientific, Karlsruhe, Germany) and used for CEC calculation. Soil $\mathrm{pH}$ was determined in $0.01 \mathrm{M} \mathrm{CaCl}_{2}$, according to DIN EN 15933:2012-11. The EC was measured in deionized water, based on DIN CEN/TS 15937:2013-08. For pH and EC analyses, air-dried and sieved soil samples were used. Total nitrogen content (TN) was analyzed in milled, oven-dried soil with a CHNS Analyzer (vario MicroCUBE, Elementar Analysensysteme $\mathrm{GmbH}$, Langenselbold, Germany).

\subsection{Soil structure indicators}

The bulk density (BD) and the WSA fraction are indicators to assess the influence of agricultural practices on soil structural stability and soil aeration [36, 45, 61]. Larger 
WSA fractions are indicative for a higher soil structural stability [36]. The WSA fraction (soil aggregates $>0.2 \mathrm{~mm}$ ) of 1-2 mm aggregate fraction was measured with the wetsieving procedure, described in Buchmann et al. [11]. In brief, $10 \mathrm{~g}$ of $1-2 \mathrm{~mm}$ aggregates $\left(M_{\text {total }}\right)$ were submerged in deionized water on a $0.2 \mathrm{~mm}$ sieve for $10 \mathrm{~min}$. Then, 20 manual $5 \mathrm{~cm}$ oscillations in deionized water were conducted within $1 \mathrm{~min}$ and the remnants on the sieve were dried at $105^{\circ} \mathrm{C}$ for $24 \mathrm{~h}$ and then weighed $\left(M_{\text {aggregates }+ \text { sand }}\right)$. Sand fraction of soil was determined by dispersing $5 \mathrm{~g}$ of $1-2 \mathrm{~mm}$ aggregates in $20 \mathrm{~mL}$ sodium hexametaphosphate $(0.01 \mathrm{M})$ in $50 \mathrm{~mL}$ centrifuge tubes within $24 \mathrm{~h}$ on a horizontal shaker. Subsequently, the dispersion was poured over a $63 \mu \mathrm{m}$ sieve and the remnants on the sieve were dried at $105^{\circ} \mathrm{C}$ for $24 \mathrm{~h}$ and then weighed $\left(\mathrm{M}_{\text {sand }}\right)$. The WSA fraction was calculated with Eq. 1:

$W S A(\%)=\frac{\left(M_{\text {aggregates }+ \text { sand }}-M_{\text {sand }}\right)}{\left(M_{\text {total }}-M_{\text {sand }}\right)} \cdot 100$

Dry BD was determined according to DIN ISO 11272:201406 . Briefly, soil cores were sampled with stainless steel soil sampling rings $(\mathrm{d}=5 \mathrm{~cm}, \mathrm{~h}=5 \mathrm{~cm})$ in the $0-5 \mathrm{~cm}$ soil layer. The weight of each soil core was corrected by subtracting the water content, gravimetrically determined after drying at $105^{\circ} \mathrm{C}$, and finally divided by the volume of the sampling ring.

\subsection{Characterization of SOM}

The SOC was used to quantify SOM, whereas its ratio to TN, the $\mathrm{C}: \mathrm{N}$ ratio, indicates degradability and transformation velocity of SOM [32]. The soil microbial biomass was quantified by soil microbial carbon (MBC), whereas its ratio to microbial biomass nitrogen (MBN), MBC:MBN, and to SOC, $M B C: S O C$, were used to estimate the microbial community composition and the quantity of nutrients in microbial biomass [46]. The MBC and DOC have both rapid turnover rates and can thus serve as indicators for changes in SOM e.g. due to management practices [21]. To identify potential changes in different SOM pools, the SOM was separated depending on density into free (frSOM), aggregate occluded (oSOM) and mineral associated SOM (aSOM). According to their turnover rates, these SOM fractions are associated to the active, intermediate and passive SOM pool, respectively [64].

\subsubsection{Analysis of MBC and MBN}

The chloroform-fumigation method was used to determine $M B C$ and $M B N$, represented as the difference in $C$ and $\mathrm{N}$ between fumigated and non-fumigated soil samples $[6$, 62]: For fumigation, $20 \mathrm{~g}$ of field-fresh soil were filled in glass jars and fumigated with chloroform in an evacuated desiccator for $24 \mathrm{~h}$. Afterwards, soil samples were filled in $100 \mathrm{~mL}$ PE bottles, $80 \mathrm{~mL}$ of $0.5 \mathrm{M} \mathrm{K}_{2} \mathrm{SO}_{4}$ solution were added and shaken for 30 min on a horizontal shaker (Kreisschüttler 3015, GFL, Burgwedel, Germany). Finally, the extraction solutions were filtered over paper filters (MN 615 1/4, Macherey-Nagel, Düren, Germany). The extraction solution of the non-fumigated soil samples was obtained by following the same procedure without the fumigation step. Carbon content in extraction solutions was determined with TOC analyzer (multiNC 2011S, Analytik Jena AG, Jena, Germany), whereas the nitrogen content was determined with the ninhydrin method described in Joergensen and Brookes [27]: Ninhydrin reactive nitrogen was quantified photometrical at $570 \mathrm{~nm}$ (Specord50, Analytik Jena $\mathrm{GmbH}$, Jena, Germany).

\subsubsection{Analysis of SOC and DOC}

The SOC was measured in accordance with Harris et al. [20]. Briefly, carbonates were dissolved by fumigation of the soil samples with concentrated $\mathrm{HCl}(12 \mathrm{M})$ for $6 \mathrm{~h}$. After soil drying for $4 \mathrm{~h}$ at $60^{\circ} \mathrm{C}$, the carbon content of the soil samples was measured with CHNS Analyzer (vario MicroCUBE, Elementar Analysensysteme GmbH, Langenselbold, Germany). The DOC was measured in filtrated soil extracts $(0.45 \mu \mathrm{m}, 1: 5$ soil-to-water ratio, $\mathrm{w} / \mathrm{v}$ ) of field-fresh soil samples via TOC analyzer (multiNC 2011S, Analytik Jena AG, Jena, Germany) according to DIN EN 1484:1997-05. The $\mathrm{C}: \mathrm{N}$ ratios correspond to the SOC divided by the TN of the same sample.

\subsubsection{Separation of SOM into frSOM, OSOM and aSOM fractions by density fractionation}

The density fractionation was conducted in an adapted method, principally based on the methods described by Cerli et al. [13] and Ontl et al. [49]: $10 \mathrm{~g}$ of air-dried, sieved soil $(<2 \mathrm{~mm})$ were filled in $50 \mathrm{~mL}$ centrifuge tubes and $30 \mathrm{~mL}$ of sodium polytungstate solution $\left(1.6 \mathrm{~g} \mathrm{~cm}^{-3}\right)$ were added. When the soil was completely wetted, the centrifuge tubes were turned upside-down five times. After 60 min of resting, the suspensions were centrifuged for 20 min at $5600 \mathrm{~g}$ (Heraeus Multifuge 4KR, Thermo Fisher Scientific, Waltham, USA). The supernatants were filtered through a $20 \mu \mathrm{m}$ nylon filter (Carl Roth $\mathrm{GmbH}+$ Co.KG, Karlsruhe, Germany). The SOM remaining on the filter was cleaned with deionized water, dried at $60^{\circ} \mathrm{C}$ and quantified gravimetrically (frSOM). Once again, $30 \mathrm{~mL}$ of sodium polytungstate solution were added to the centrifuge tubes with the soil, followed by a re-suspendation step on a vortexer $(2 \times 2 \mathrm{~s})$ before disrupting the soil aggregates with an ultrasonic probe $\left(350 \mathrm{~J} \mathrm{~mL}^{-1}\right.$ ) (Sonoplus HD 2070, Bandelin 
electronics GmbH \& Co.KG, Berlin, Germany). After resting for $60 \mathrm{~min}$, the suspension was centrifuged for $20 \mathrm{~min}$ at $5600 \mathrm{~g}$ and the supernatants were filtered over a $20 \mu \mathrm{m}$ nylon filter. The SOM remaining on the filter was cleaned with deionized water, dried at $60^{\circ} \mathrm{C}$ and quantified gravimetrically (oSOM). The aSOM fraction was obtained by subtracting frSOM and OSOM from the total SOM. Total SOM was obtained by multiplying the $\mathrm{SOC}$ values by a factor of 2 [7]. A density fractionation was conducted only at $\mathrm{T} 0$ and $\mathrm{T} 2$, because of its labor- and cost-intensity.

\subsection{Statistical analyses}

In both treatments (PC and NC), five composite samples were taken (from five randomly- selected plots) in each soil layer at each sampling, respectively, resulting in respectively five replicates per soil layer per sampling per treatment. Mixed factorial ANOVAs with coverage time (sampling) and soil layer as repeated factors and treatment as fixed factor were performed to determine significant differences between means. If significant interaction effects were occurring, additional ANOVAs, with least significance distance (LSD) testing as post-hoc test, were applied to identify significant differences. Differences were reported as statistically significant if the probability of error was $<0.05$. Variance homogeneity was confirmed with Levene's test. Normality distribution was examined graphically, using histograms and quantile-quantile plots. Correlation of two variables was estimated with Pearson's correlation coefficient or Spearman's $\rho$ if the data were not normally distributed. All statistical analyses were conducted with IBM SPSS Statistics 23 and Microsoft Excel 2010.

\section{Results}

\subsection{Soil temperature and moisture}

The daily mean soil temperature under PC and NC, corresponding to each soil depth $(5,15$ and $35 \mathrm{~cm})$, and the mean ambient temperature ( $2 \mathrm{~m}$ above ground) are shown in Fig. 1. In both treatments, the soil temperature profile followed that of the ambient temperature and was mostly higher than the ambient temperature. The soil temperature and moisture data exhibits a data gap from July to mid-August, due to technical malfunction of the measuring station. During the observed time period, 12 August-November, the soil temperature was always higher under PC than under NC (Table S41, Online Resource). This effect was observed at all soil depths. In August, the monthly mean soil temperature at 5,15 and $35 \mathrm{~cm}$ soil depth was by $2.0 \pm 1.4,1.4 \pm 0.5$ and $0.7 \pm 0.4{ }^{\circ} \mathrm{C}$ higher under PC than under NC. In both treatments, soil temperature was highest in the surface soil and decreased with soil depth in August and the first half of September. From October on, the opposite effect, an increasing temperature with soil depth, was observed. Differences in soil temperature between PC and NC decreased with soil depth and from August until November. Largest soil temperature differences between $\mathrm{PC}$ and $\mathrm{NC}$ occurred at $5 \mathrm{~cm}$ soil depth and were up to $6^{\circ} \mathrm{C}$ at midday on sunny days in August. The maximum temperature under PC reached $34.2^{\circ} \mathrm{C}$ at $5 \mathrm{~cm}$ soil depth and it coincided with the highest ambient temperature.

Soil moisture (Fig. 2) was lower under PC compared with $\mathrm{NC}$ at all soil depths over the observed timed period (exception: $15 \mathrm{~cm}$ soil depth at the end of October/ November), with differences of up to $11 \%$. In general, soil moisture increased with soil depth in both treatments (exception; $15 \mathrm{~cm}$ soil depth under NC at the end of October/November). Precipitation events were followed by a direct increase in soil moisture at all soil depths of both treatments. These increases in soil moisture were considerably larger under NC than under PC, especially at both upper soil depths.

\subsection{Physicochemical soil properties}

The CEC at TO was $1064 \pm 52,1059 \pm 33$ and $1071 \pm 36 \mathrm{mmol} \mathrm{kg}^{-1}$ under PC and $973 \pm 19,1019 \pm 62$ and $1026 \pm 20 \mathrm{mmol} \mathrm{kg}^{-1}$ under NC, respectively in the $0-10$, $10-30$ and $30-60 \mathrm{~cm}$ soil layers.

At T0 (late-July, 1 week after strawberry transplanting), pH (Fig. 3a) varied between 7.7 and 7.9, decreased to 7.5-7.6 at T1 (late-September) and remained constant until T2 (late-November). During the sampling period, the $\mathrm{pH}$ showed no clear dependence on soil depth or cover type.

Compared to PC, the EC (Fig. 3b) under NC was higher at T0 and T1 and significantly lower at T2 $(p=0.016)$ in the $0-10 \mathrm{~cm}$ soil layer. In both treatments, the EC in the $0-10 \mathrm{~cm}$ soil layer was higher at T0 and T1 (significantly in NC: $p<0.016$ ) and lower at T2 (significantly in NC; $p<0.002$ ) compared to both sub-surface soil layers. During the sampling period, the EC dropped in the $0-10 \mathrm{~cm}$ soil layer of both treatments (significantly in NC: $p=0.001$ ). In both sub-surface soil layers, the EC ranged between 152-174 $\mu \mathrm{S} \mathrm{cm}^{-1}$ and showed no differences between treatment, soil depth and sampling time.

The TN (Fig. 3c) ranged between $0.07-0.14 \%$ and showed a trend towards slightly higher TN under PC compared to NC in all soil layers at T1 and T2 (exception: $30-60 \mathrm{~cm}$ soil layer at T2). In both treatments, the TN decreased significantly during the sampling period $(p<0.001)$. This decrease was stronger from $\mathrm{T} 1$ to $\mathrm{T} 2$ than from T0 to T1. In both treatments, the TN in the $30-60 \mathrm{~cm}$ 
Fig. 1 Soil and air temperature a-c Daily mean soil temperature in strawberry cultivation, measured at 5, 15 and $35 \mathrm{~cm}$ soil depth under plastic coverage (PC) and no coverage (NC), respectively, and daily mean air temperature measured $2 \mathrm{~m}$ above ground. The data gap in soil temperature from July to mid-August was due to a technical malfunction of the measuring station
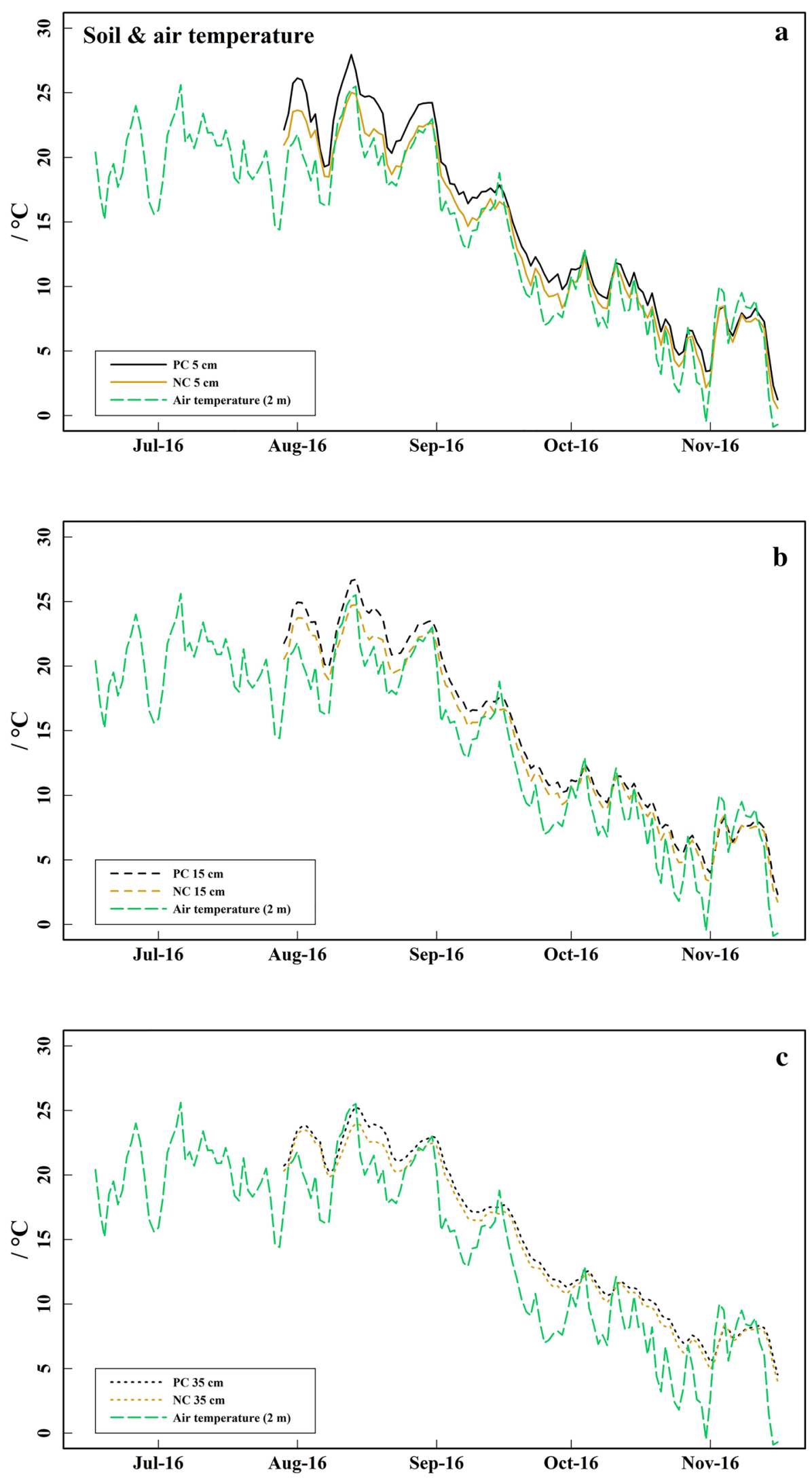


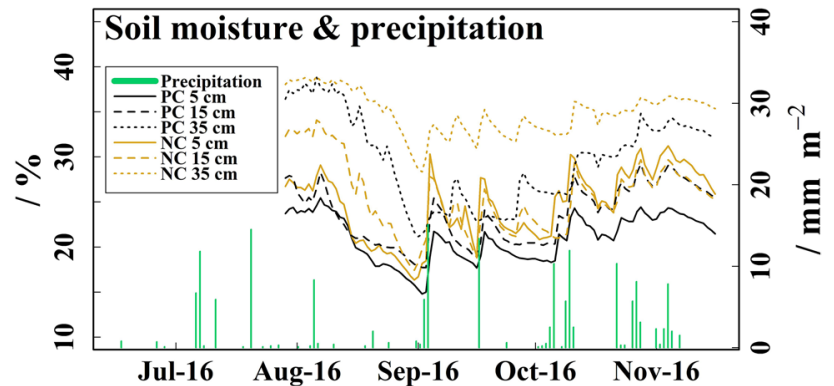

Fig. 2 Daily mean soil moisture in strawberry cultivation, measured at 5,15 and $35 \mathrm{~cm}$ soil depth under plastic coverage (PC) and no coverage (NC), respectively, and daily precipitation. The data gap in soil moisture from July to mid-August was due to a technical malfunction of the measuring station

soil layer was significantly lower than in both soil layers above $(p<0.005)$.

\subsection{Soil structure indicators}

The BD in the $0-5 \mathrm{~cm}$ soil layer was $1.23 \pm 0.10,1.21 \pm 0.02$ and $1.25 \pm 0.05 \mathrm{~g} \mathrm{~cm}^{-3}$ under $P C$ and $1.18 \pm 0.06$, $1.23 \pm 0.06$ and $1.12 \pm 0.05 \mathrm{~g} \mathrm{~cm}^{-3}$ under NC at T0, T1 and
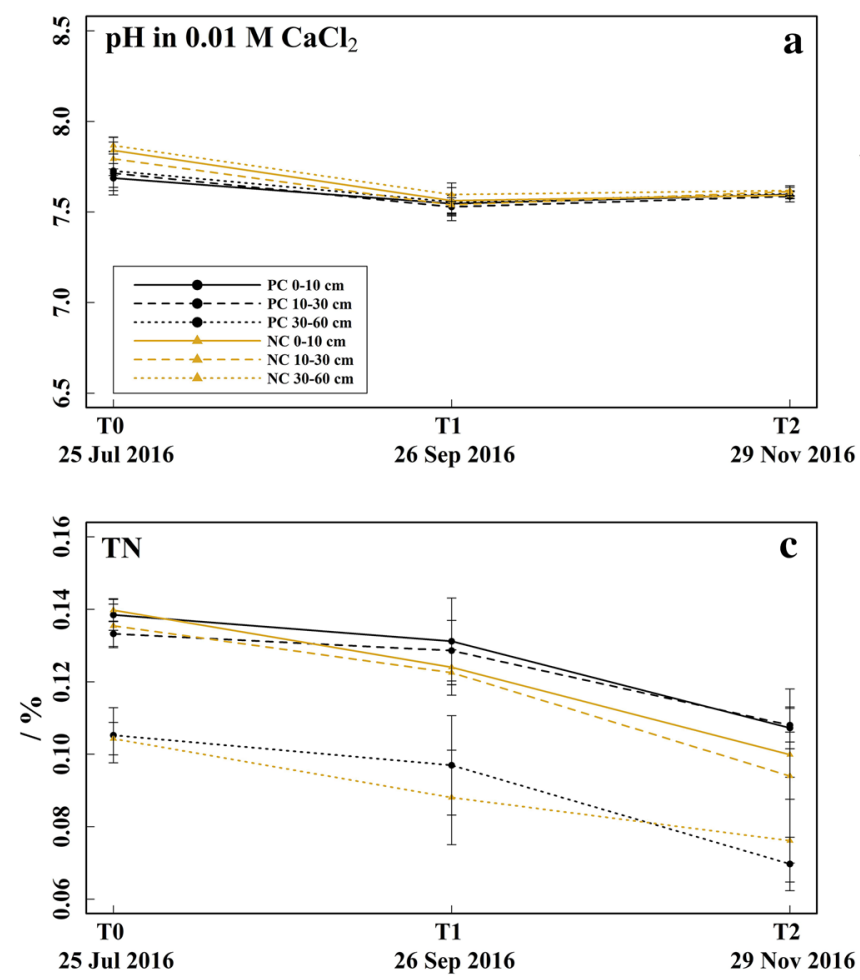

Fig. 3 Physicochemical soil properties a pH (in $0.01 \mathrm{M} \mathrm{CaCl}_{2}$ ) determined immediately after strawberry plantation (T0), 2 months (T1) and 4 months (T2) in the $0-10,10-30$ and $30-60 \mathrm{~cm}$ soil layer
$\mathrm{T} 2$, respectively. The $\mathrm{BD}$ results showed only small variation between treatment and sampling time. Only at $\mathrm{T} 2$, the BD was significantly higher under PC compared to NC $(p=0.049)$.

Higher WSA fractions (Fig. 3d) were measured under NC at $\mathrm{T} 0$ and $\mathrm{T} 1$ than under $\mathrm{PC}$, whereas at $\mathrm{T} 2$ no differences were observed. In both treatments, the WSA fractions showed a similar pattern: they increased from $30-41 \%$ at T0 to $40-51 \%$ at T1 and decreased afterwards to $28-32 \%$ at T2. Overall, no effects of the soil layers were observable in the WSA fractions.

\subsection{Soil organic matter characteristics}

\subsubsection{Soil microbial biomass characteristics}

The MBC (Fig. 4a) ranged between 63.9-510.4 $\mathrm{mg} \mathrm{kg}^{-1}$. At T0 and T1, MBC was lower under PC than under NC (significantly at $10-30$ and $30-60 \mathrm{~cm}, p<0.028$ ), whereas at $\mathrm{T} 2$, the opposite was observed. In both treatments, $\mathrm{MBC}$ increased significantly from T0 to T1 $(p<0.001)$. In PC, the $M B C$ increased further from $T 1$ to $T 2$, whereas the MBC decreased in NC. The strongest increase in MBC under PC was found in the $10-30 \mathrm{~cm}$ soil layer. In both treatments,
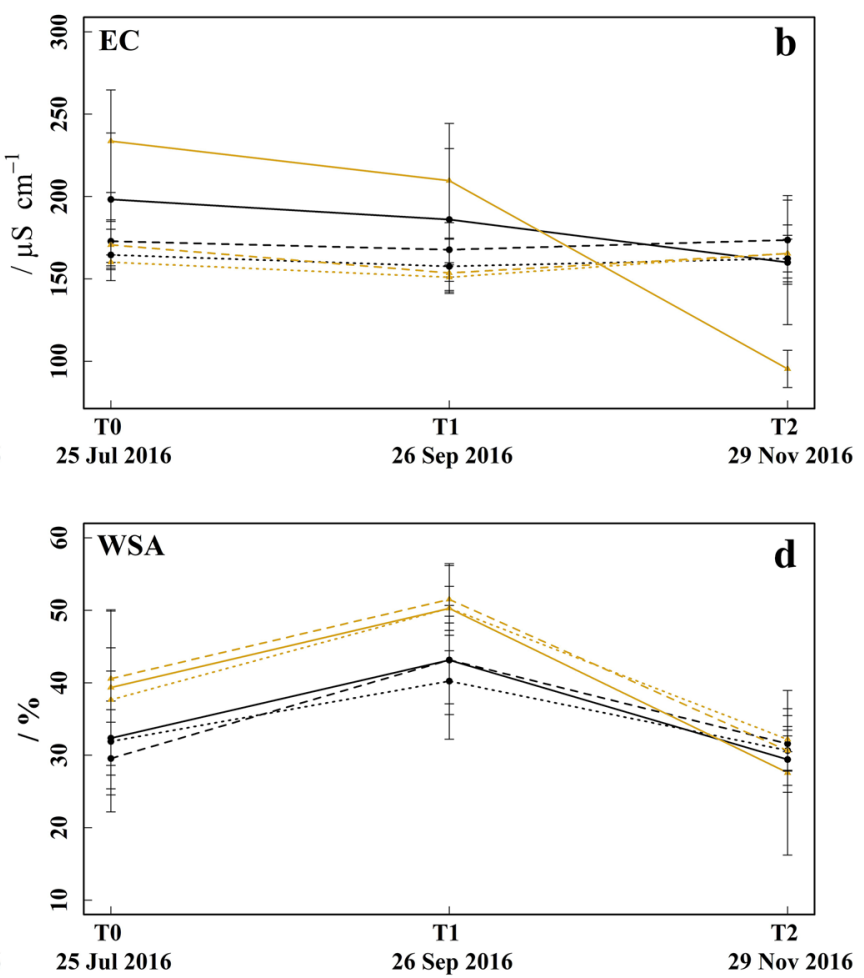

under plastic coverage (PC) and no coverage (NC), respectively, shown as mean with standard deviation $(n=5)$. b Electrical conductivity (EC), c total nitrogen (TN), $\mathbf{d}$ water-stable aggregates (WSA) 
Fig. 4 Soil microbial biomass a Soil microbial biomass carbon (MBC) determined immediately after strawberry plantation (T0), 2 months (T1) and 4 months (T2) in the $0-10,10-30$ and $30-60 \mathrm{~cm}$ soil layer under plastic coverage (PC) and no coverage (NC), respectively, shown as mean with standard deviation $(n=5)$. b Soil microbial biomass nitrogen (MBN), c MBC:MBN ratio
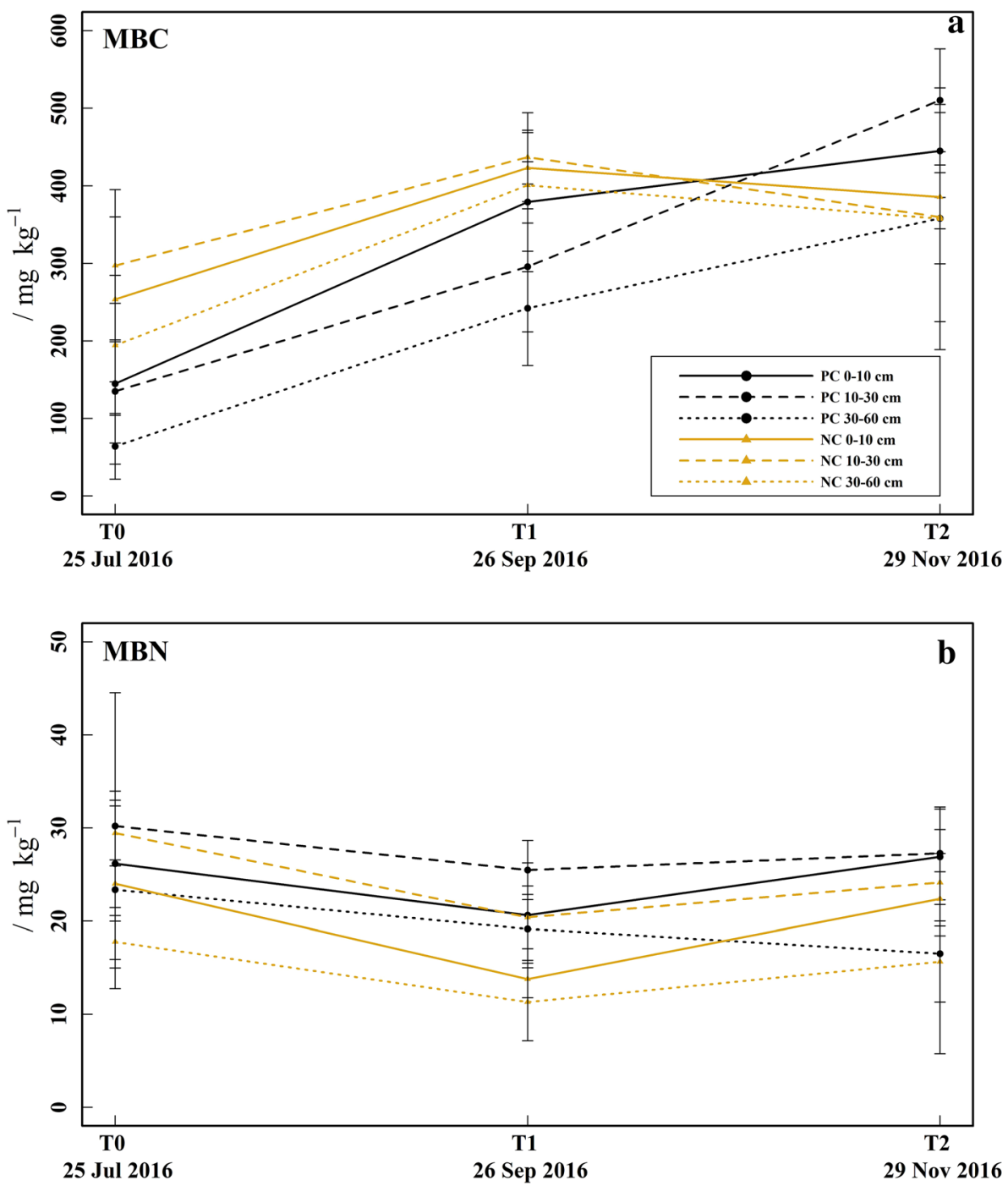
the lowest values for $M B C$ were measured in the $30-60 \mathrm{~cm}$ soil layer.

The MBN (Fig. 4b) ranged between 11.3-30.2 $\mathrm{mg} \mathrm{kg}^{-1}$ and was significantly higher under PC compared to NC $(p=0.002)$. Generally, MBN decreased from T0 to T1 and increased again from $\mathrm{T} 1$ to $\mathrm{T} 2$ in both treatments. With respect to all other soil layers, MBN was highest in the root layer of both treatments.

The MBC:MBN ratios (Fig. 4c) ranged between 3.1-53.5. At T1, the MBC:MBN ratios were lower under PC compared with NC, whereas no clear differences were observed between treatments at T0 and T2. Under PC, MBC:MBN ratios became significantly wider from T0 to T2 $(p=0.013)$. Under NC, MBC:MBN ratios showed a significant increase $(p=0.003)$ from T0 to T1, whereas from T1 to T2, the ratios dropped again significantly $(p=0.014)$ but were still larger than at T0. The $C: \mathrm{N}$ ratios correlated positively with the MBC:MBN ratios $(r=0.291, p=0.005)$.

\subsubsection{SOC, DOC, C:N and MBC:SOC ratio}

The SOC (Fig. 5a) ranged between $0.84-1.16 \%$ and showed slightly higher values under PC compared to NC. From T0 to $\mathrm{T} 1$, the SOC increased significantly in all soil layers in both treatments $(p<0.001)$, whereas from T1 to T2, the SOC remained nearly constant. In both treatments, SOC was significantly lower in the $30-60 \mathrm{~cm}$ soil layer compared with both soil layers above $(p<0.005)$.

At T2, the highest DOC value $\left(26.9 \mathrm{mg} \mathrm{kg}^{-1}\right)$ was found in the $0-10 \mathrm{~cm}$ soil layer under NC (Fig. $5 \mathrm{~b}$ ), which differed significantly from the PC treatment $(p<0.001)$. Under NC, the DOC increased in both upper soil layers during the sampling period, significantly in the $0-10 \mathrm{~cm}$ soil layer from T1 to T2 $(p<0.001)$, whereas in the $30-60 \mathrm{~cm}$ soil layer, there was a strong decrease in DOC from T0 to T1, followed by an increase back to the initial level from $\mathrm{T} 1$ to T2. Under PC, only small fluctuations on DOC levels were observed.

No differences were observed in the C:N ratios between both treatments (Fig. $5 \mathrm{c}$ ). At T0, the values ranged between 7.1-8.7 and increased significantly during the sampling period to $10.6-15.1$ at T2 $(p=0.001)$. In both treatments, the $\mathrm{C}: \mathrm{N}$ ratios increased with soil depth, however, not significant.

The MBC:SOC ratios (Fig. $5 \mathrm{~d}$ ) ranged between $0.7-4.4 \%$. At T0 and T1, the MBC:SOC ratios were lower under PC compared with $\mathrm{NC}$, whereas the $\mathrm{MBC}: \mathrm{SOC}$ ratios were slightly higher under PC compared with NC at T2 (exception: $30-60 \mathrm{~cm}$ soil layer). In both treatments, the MBC:SOC
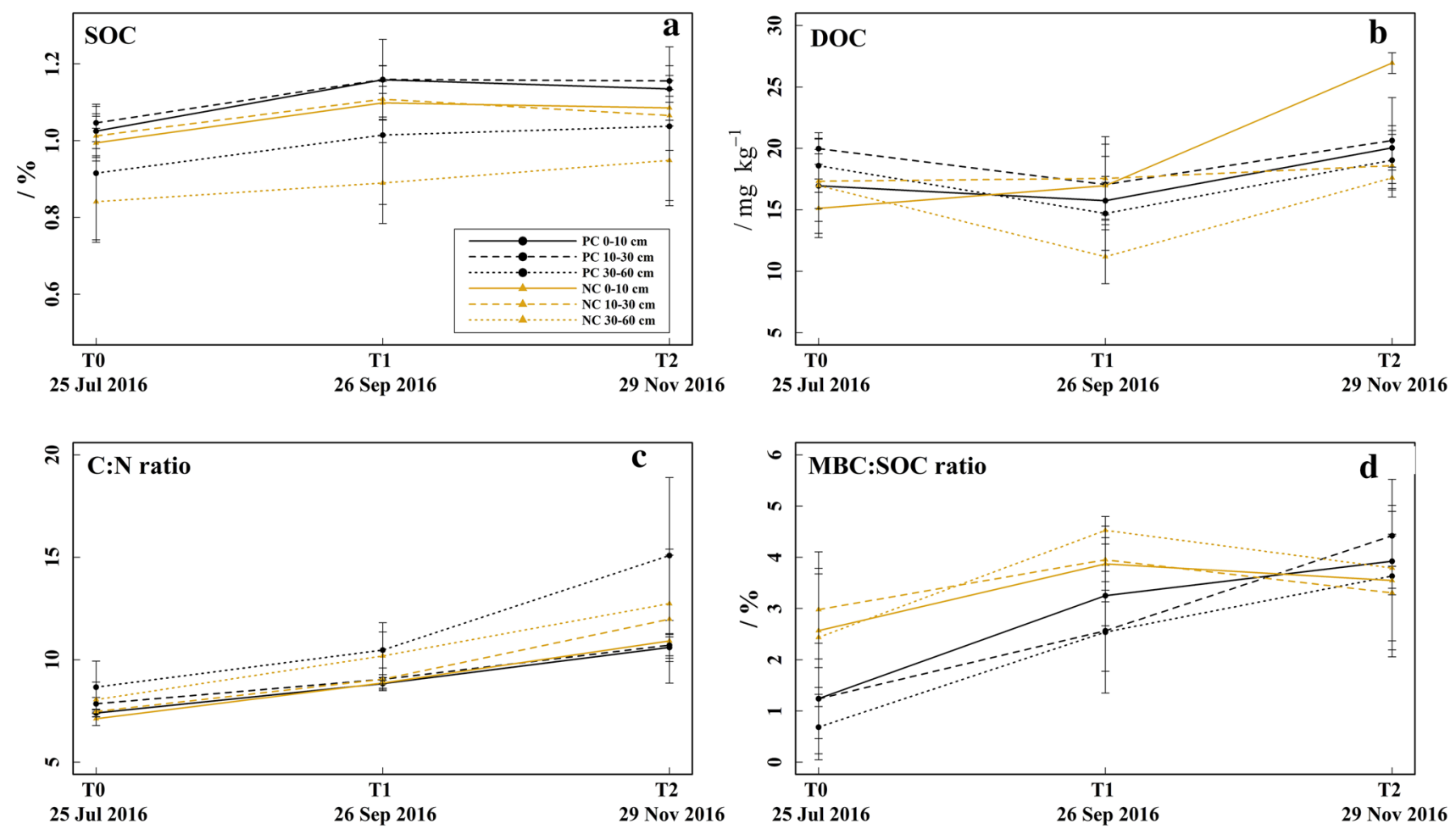

Fig. 5 Soil organic matter a Soil organic carbon (SOC) determined immediately after strawberry plantation (T0), 2 months (T1) and 4 months (T2) in the $0-10,10-30$ and $30-60 \mathrm{~cm}$ soil layer under

plastic coverage (PC) and no coverage (NC), respectively, shown as mean with standard deviation $(n=5)$. b Dissolved organic carbon (DOC), c C:N ratio, $\mathbf{d}$ MBC:SOC ratio 
ratios increased from T0 to T2 (significantly under PC: $p=0.001$ ).

\subsubsection{SOM fractions}

The values for frSOM, OSOM and aSOM fractions, separated by density fractionation, ranged between 1.0-3.7, 1.1-7.2 and 10.4-19.5 $\mathrm{g} \mathrm{kg}^{-1}$, respectively (Fig. 6a-c). The aSOM fraction showed a slight impact of treatment with the highest values found under PC at T2 (significant in the $10-30 \mathrm{~cm}$ soil layer: $p=0.017$ ). In both treatments, the aSOM fractions increased significantly from TO to T2 $(p<0.001)$, whereas the frSOM and oSOM fractions decreased significantly from T0 to T2 $(p<0.004)$.

\section{Discussion}

\subsection{Soil temperature and moisture}

Our results corroborate the well described increase of soil temperature under PC compared to NC (e.g. [70]) as well as the decreasing influence of $\mathrm{PC}$ on soil temperature with increasing soil depth [37, 52]. Former studies mostly focused on the impact of PM on the surface soil layer (e.g. $[47,73])$ but we found temperature increases even at $35 \mathrm{~cm}$ soil depth under PC compared to NC. This confirmed our assumption that also deeper soil layers should be included, when investigating the influence of PC on soil processes, especially as soil temperature is seen as a main driver of PC-effects on soil (e.g. [19]). Differences in soil temperature decreased during the sampling period from July to November and revealed hence a strong seasonal effect.

Because PC reduces evaporation, it is often used to increase the water content in soil, especially in arid and semiarid climates (e.g. [40, 70]). In contrast to this, we found lower soil moisture under PC than in the uncovered soil. Similarly, Schirmel et al. [54] reported lower soil moisture under PC compared to organic mulching in strawberry cultivation in southwestern Germany. We attributed this mainly to additional water inputs from rainfall events. In NC treatment, precipitation water infiltrates the soil directly as observed by increasing soil moisture after rainfalls (Fig. 2). Under PC, only a fraction of the rainfalls reaches the soil, presumably through lateral water flow from the furrows induced by lateral pressure heads [53], resulting in a lower increase of soil moisture after rainfalls. Furthermore, higher transpiration rates of the plants under PC due to higher soil temperatures [67] might also affect differences in soil moisture between treatments. We conclude from our results that the reduced water infiltration after rainfalls (and the higher transpiration losses of the plants) under PC overbalances the water saving effect of PC due to mitigated evaporation in our study. Our soil temperature and moisture results confirm our basic assumption that PC shifts soil temperature and moisture and thus, the microclimate in the establishment phase of the strawberries, although the reduced soil moisture was the opposite of the expected direction.

\subsection{Effects on leaching processes}

The lower EC decrease under PC compared to NC during the sampling period in the surface soil layer $(0-10 \mathrm{~cm})$ indicates that $\mathrm{PC}$ can reduce leaching processes by impeding rainfall infiltration as displayed by the lower soil moisture under PC. The slight EC drop under PC between lateJuly and late-November (T0-T2) in the surface soil layer can be attributed to the nutrient uptake of the growing strawberry plants [34]. The larger EC drop under NC between late-July and late-November occurred likely
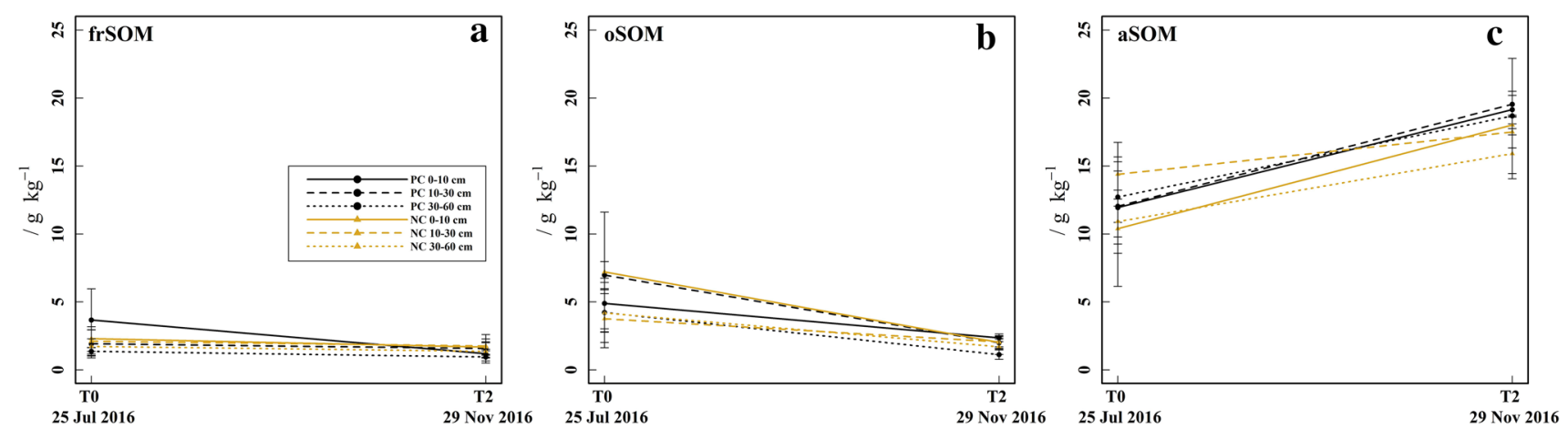

Fig. 6 Soil organic matter fractions separated by density fractionation. a Free soil organic matter (frSOM) determined immediately after strawberry plantation (T0) and 4 months (T2) in the 0-10, $10-30$ and $30-60 \mathrm{~cm}$ soil layer under plastic coverage (PC) and no coverage (NC), respectively, shown as mean with standard deviation $(n=5)$. b Aggregate occluded soil organic matter (oSOM). c Mineral associated soil organic matter (aSOM) 
due to an increased leaching caused by larger rainfall amounts and an increasing water saturation of the soil. Reduced leaching under PC is additionally supported by the smaller TN reduction under PC compared to NC during the sampling period in both upper soil layers. We attribute the TN decrease in both treatments, during the establishment phase of the strawberries to plant uptake of nitrogen and microbial mediated denitrification processes [7, 67], whereas the difference in TN between treatments in late-September (T1) and late-November (T2) presumably occurred due to reduced nitrogen leaching and impeded ammonia volatilization under PC [67]. The higher TN value under NC in the $30-60 \mathrm{~cm}$ soil layer in late-November might be interpreted as an accumulation of nitrogen leachate in the subsoil. The higher TN in both upper soil layers under $P C$ indicate that the reduced nitrogen leaching under PC can overbalance the expected higher nitrogen loss under PC by increased plant uptake and larger microbial denitrification processes (higher MBC) $[34,67]$. The differences in leaching between both treatments did not influence the $\mathrm{pH}$. The slight drop in soil $\mathrm{pH}$ from July to September (T0-T1) can be attributed to the $\mathrm{H}^{+}$entry of the growing strawberry plants, induced by their root exudation and respiration [7]. Generally, these reduced leaching processes can point to a better nutrient (fertilizer) use efficiency under PC, which can reduce the applied amounts of mineral fertilizers, and potentially mitigate groundwater contamination with nitrate.

\subsection{Effects on soil aggregation}

Plastic coverage can impede the mechanical impact of raindrops at soil surface as well as aggregate slaking after rainfalls [31]. Therefore, we hypothesized that this will increase the WSA fraction in the surface layer, however, this was not confirmed at all by our results. Possibly the fast-growing strawberry leave canopy strongly mitigated the mechanical impact of rainfall events on soil surface. Unexpectedly, we found larger WSA fractions under NC compared to PC in late-July (T0). As microbial exudates are known to promote aggregate formation [36], the also higher MBC under NC at this time might have caused the larger WSA fractions (reasons for the differences in MBC discussed in microbiology section). These differences between PC and NC treatment in WSA fractions were still observable in late-September. We attributed the general increase of the WSA fractions in both treatments from late-July to late-September to the mechanical impact and the root exudation of growing strawberry roots, the increased microbial exudation induced by higher microbiological activity, and the decreased soil moisture $[7,36]$. We assume that in the colder and wetter season ( $\mathrm{T} 1$ to $\mathrm{T} 2$ ), the reduced microbial and root exudation, the dying-off of the strawberry roots and the increasing soil moisture decreased the WSA fractions again. This decrease was smaller under PC and balanced out the initial differences in WSA fractions between PC and NC. We suggest that the higher temperatures under $P C$ decelerate the root dyingoff and mitigated the reduction of root and microbial exudation which in turn might be responsible for the smaller decrease in WSA fractions. The changes in the WSA fraction seemed to have no influence on BD. We found a significantly lower BD under NC compared to PC in late-November, which we attributed to higher bioturbation induced by an increased earthworm activity under NC $[54,56]$ and to extended soil pores induced by moderate frost in the night before the respective sampling.

\subsection{Soil organic matter characteristics}

\subsubsection{Effects on microbial biomass growth and composition}

The $M B C$ results confirmed our hypothesis, that altered microclimatic conditions under PC enhance microbial growth. Generally, increased MBC values mostly correspond either directly to higher soil temperature and soil moisture $[3,5,57]$ or to increased root biomass and root exudation triggered by higher soil temperature and soil moisture $[1,34,71]$. Thus, we attribute the strong increase in $\mathrm{MBC}$ in both treatments between late-July and lateSeptember to an increased root biomass entry of the growing strawberry plants, which is known to stimulate microbe proliferation [46]. Between late-September and late-November, the MBC still increased under PC while it dropped under NC. We link this drop to the lower temperatures (night frost) under NC, which inhibit the temperature-sensitive plant and microbial biomass growth [36, 50], whereas higher temperatures under PC still maintain plant and microbial biomass growth. Thus, PC can extend the active phase of the microbes. The lower MBC values under PC compared to NC in late-September can be interpreted as an effect of the lower soil moisture under PC but also as a relic of the initial differences between treatments. These initial differences were unexpected but according to the farmer, a possible explanation could be that during strawberry transplanting in mid-July, the field was twice irrigated with an aboveground sprinkler system with circular movement, which presumably caused an uneven irrigation pattern. Furthermore, larger MBN values under PC corroborate our hypothesis of an enhanced microbial biomass under PC. But the MBN values show a different pattern compared with $M B C$ values and lead to increasing MBC:MBN ratios from late-July to late-November in both treatments, which are indicative of larger fungal fractions in the microbial community [12] and thus display a shift 
in microbial community. Because of increasing $\mathrm{C}: \mathrm{N}$ ratios during the sampling period and a positive correlation between C:N and MBC:MBN ratios, we suggest that this shift might be caused by low quality SOM entry into soil (SOM with high C:N ratios), which is known to favor fungal growth [9]. But how the fungal community composition changes and how the fungal community gets influenced by the high soil temperature and low soil moisture under $P C$ in the next summer remain unclear. Further research should clarify if the potentially changed fungal communities contain mycotoxigenic fungi genera, which can be triggered by environmental stress conditions to mycotoxin production [55]. Additionally, increasing MBC:MBN ratios are also indicative of long-term decreases in nutrient availability to soil microorganisms [28]. Beside the SOM entry, the crop rotation from winter wheat to strawberries might also have influenced the microbial community structure. It is known that, especially in the rhizosphere, microbial communities are influenced by the plant species, because of different root exudation and rhizodeposition in different root zones $[10,25]$. However, as our MBC:MBN ratios were partially markedly wider than the typical ratios of 5-10 for arable soils (reviewed in Joergensen and Emmerling [28]) and showed large standard deviations, the MBC:MBN ratios should be interpreted carefully and require further investigation on the microbial community to confirm the indicated microbial shift.

\subsubsection{Effects on organic matter input and decomposition}

The general increase of $\mathrm{SOC}$ in both treatments, especially between late-July and late-September, most likely originated from the additional root biomass entry into soil from the growing strawberry plants after seedling transplantation and the increase in microbial biomass. The higher SOC under PC in late-September and late-November was presumably caused by a favored root growth under PC application $[17,66,72]$. Our results are in contrast to the reduced SOC contents found by Li et al. [39] and several other studies (e.g. $[23,75])$ after $1-4$ months and 2-4 years of PC application, respectively. Higher decomposition rates were discussed as reason for these SOC declines, which were induced by higher soil temperatures and soil moisture under PC $[33,35,72]$. Since we found reduced soil moisture under $P C$, this might explain the contrasting results. On the other hand and in agreement with our results, some studies reported that $P C$ has no impact on SOC or even increase the SOC under PC $[16,43,66]$. As PC increases aboveground and belowground biomass $[66,70,72]$, it was argued that increased biomass productivity under PC can balance out SOC losses caused by accelerated decomposition [19]. Thus, the root biomass input in our study seemed to be more pronounced and compensates a possibly higher decomposition rate of $\mathrm{SOC}$ by larger microbial activity as indicated by the increased soil temperature and MBC values under PC. SOC and MBC are known to correlate positively with $\mathrm{DOC}$ because it derives among other from leaf litter, root exudates and decomposition and metabolic by-products [8]. But despite of the increased SOC and MBC values under PC in lateNovember, our study showed hardly any influence of PC on DOC. Only the high DOC content under NC in the $0-10 \mathrm{~cm}$ soil layer in late-November, which we attributed to the leaching of organic substances from decaying plant litter on the soil surface [8], was obviously impeded by the plastic mulch. Similarly to DOC, the C:N ratios revealed no differences between the studied treatments, but the $\mathrm{C}: \mathrm{N}$ ratios became wider in both treatments during the establishment phase of the strawberries. This might be explained by fresh SOM entering the soil by growing strawberry roots and reduced TN stocks. Wider C:N ratios point to poorly degradable litter and thus, to slower transformation and recycling of SOM [32]. This lower quality of SOM can promote fungal growth [9] and can change the microbial community towards larger fungal fractions [7] as already indicated by our MBC:MBN ratios. The $M B C: S O C$ ratios increased during the sampling period under PC, which is in line with a study by Luo et al. [44]. Under NC, the MBC:SOC ratios increased from late-July to late-September but remained constant afterwards. The large standard deviations challenged the identification of any difference between the treatments. Generally, our $\mathrm{MBC}: \mathrm{SOC}$ ratios lie within their typical range of $0.7-7 \%$ and also showed the typically occurring large seasonal variances $[68,69]$. The increasing MBC:SOC are indicative for a higher availability of SOM to soil microorganisms [28]. The initial MBC:SOC ratios below $2 \%$ under $\mathrm{PC}$ are according to Anderson [2] an indicator for reduced SOM availability and a hint to soil degradation. Thus, it might be an important point to check, if the MBC:SOC drop again below $2 \%$ in the next summer.

\subsubsection{Effects on transformation of different SOM pools}

The frSOM and OSOM fractions represent the light fraction organic matter (LFOM), which is mineralized fast and important for the short-term nutrient supply in soil [7, 63]. The LFOM decreased in both treatments during the establishment phase of the strawberries, but only under PC with a significant extent. This possibly indicates that PC enhances the LFOM mineralization, as consequence of soil warming [18], which likely triggers an increased microbial activity as suggested by our MBC results. Despite the reduced LFOM contents, the $S O C$ increased during the establishment phase of the strawberries, which showed that the increasing aSOM fraction (also referred to as heavy 
fraction organic matter (HFOM)) compensated the decline in LFOM. This might indicate that a part of the LFOM was transformed into the HFOM pool. The HFOM consists of organo-mineral complexes and is responsible for the longterm stabilization of SOM $[7,63]$. Organo-mineral formation depends on surface properties of the minerals as well as the organic compounds and it can proceed in various mechanisms. Mainly simple organic compounds undergo organo-mineral formation [7]. Because of this, we assume that the higher HFOM contents were possibly caused by increasing entry of root and microbial exudates and larger amounts of degradation products, resulting from the higher microbial activity. The assumed larger root biomass production under $\mathrm{PC}$ might have triggered the significant larger aSOM fractions under $\mathrm{PC}$ in the root zone $(10-30 \mathrm{~cm}$ soil layer) in late-November.

In summary, our results indicate a general shift in SOM composition to more SOC with larger HFOM and lower LFOM fractions, which seems to be more pronounced under PC than under NC. Thus, SOM quality is shifted from a faster mineralizable SOM towards a more stable SOM with a lower nutrient supply but with an improved nutrient sorption, water holding capacity and soil stability [7, 63]. Finally, this confirms our hypothesis of an altered SOM quality under PM. The assumed better nutrient sorption by a more stable SOM under PC might have additionally enhanced our TN and EC values under PC.

\section{Conclusions}

Our study demonstrated that PC influences various soil processes already within a 4-month period during strawberry establishment in a loamy silt soil in a temperate, humid climate with significant outcomes. These effects were not restricted to the topsoil $(0-10 \mathrm{~cm})$ but propagated to deeper soil layers, partially down to $60 \mathrm{~cm}$. The depth- and time-dependent approach of the present study allowed conclusions on transport and transformation processes in soil like leaching and accumulation of dissolved substances, but also on transformation of SOM pools due to processes like aggregation, adsorption, degradation and mineralization. The influence of PC on various soil processes within our 4-month experiment can be interpreted as mainly positive for soil quality. The PC changed the soil microclimate in the strawberry establishment phase by increasing soil temperature and reducing soil moisture. The reduced soil moisture under PC emphasizes that in a temperate, humid climates the impeded rainfall infiltration and higher transpiration losses of plants can compensate the water-saving through reduced evaporation. Reduced leaching processes under PC are indicated by an enhanced EC and TN, which can improve nutrient supply and fertilizer usage. The increased soil temperature under PC extends the microbial growth period and increased microbial biomass at the end of our sampling period, indicating higher SOM losses by microbial decomposition. However, PC also increased SOC content in the establishment phase of strawberries and thus overbalances the potentially higher SOM losses by microbial decomposition with higher biomass inputs resulting from stronger root and microbial growth. Additionally, PC changes SOM quality due to an enhanced shift in SOM towards a higher SOC with larger HFOM and lower LFOM fractions. This indicates a reduced fast mineralizable $S O M$ pool, resulting in a lower nutrient supply, but on the other hand a larger stable SOM pool with larger nutrient sorption, water holding and soil stability. Studies on larger scale are advisable to check if our findings are generalizable on landscape levels. Future long-term studies should assess how PC influence soil processes over a complete season and in the commonly multi-annual application of PC.

Acknowledgements We want to thank $C$. Steegmüller for providing access to the sampling site and for his expertise on strawberry cultivation and Katharina Lühmann, Maria Olivares and Sirma Scopchanova for valuable assistance during sample analysis. Furthermore, we would like to thank Prof. S. Thiele-Bruhn (University of Trier) for providing the field measuring station.

Funding This work was supported by the Ministry for Education, Sciences, Further Education and Culture of the State of RhinelandPalatinate (MBWWK) in the frame of the Interdisciplinary Research Group for Environmental Studies (IFG-Umwelt) of University KoblenzLandau, by the Prof. B. Gedek and W. Gedek foundation and by the research fund of the University of Koblenz-Landau. Open Access funding enabled and organized by Projekt DEAL.

\section{Compliance with ethical standards}

Conflict of interest The authors declare that they have no competing interests.

Open Access This article is licensed under a Creative Commons Attribution 4.0 International License, which permits use, sharing, adaptation, distribution and reproduction in any medium or format, as long as you give appropriate credit to the original author(s) and the source, provide a link to the Creative Commons licence, and indicate if changes were made. The images or other third party material in this article are included in the article's Creative Commons licence, unless indicated otherwise in a credit line to the material. If material is not included in the article's Creative Commons licence and your intended use is not permitted by statutory regulation or exceeds the permitted use, you will need to obtain permission directly from the copyright holder. To view a copy of this licence, visit http://creativecommons .org/licenses/by/4.0/. 


\section{References}

1. An T, Schaeffer S, Li S et al (2015) Carbon fluxes from plants to soil and dynamics of microbial immobilization under plastic film mulching and fertilizer application using $13 \mathrm{C}$ pulse-labeling. Soil Biol Biochem 80:53-61. https://doi.org/10.1016/j.soilb io.2014.09.024

2. Anderson T-H (2003) Microbial eco-physiological indicators to asses soil quality. Agric Ecosyst Environ 98:285-293. https://doi. org/10.1016/S0167-8809(03)00088-4

3. Andrade DS, Colozzi-Filho A, Giller KE (2003) The soil microbial community and soil tillage. In: El Titi A (ed) Soil tillage in agroecosystems. CRC Press, Boca Raton, pp 51-81

4. Ashworth J, Keyes D, Kirk R, Lessard R (2001) Standard procedure in the hydrometer method for particle size analysis. Commun Soil Sci Plant Anal 32:633-642. https://doi.org/10.1081/CSS100103897

5. Belay-Tedla A, Zhou X, Su B et al (2009) Labile, recalcitrant, and microbial carbon and nitrogen pools of a tallgrass prairie soil in the US Great Plains subjected to experimental warming and clipping. Soil Biol Biochem 41:110-116. https://doi. org/10.1016/j.soilbio.2008.10.003

6. Blume H-P (2000) Handbuch der Bodenuntersuchung: Terminologie, Verfahrensvorschriften und Datenblätter; physikalische, chemische, biologische Untersuchungsverfahren; gesetzliche Regelwerke. Grundwerk, Beuth

7. Blume H-P, Brümmer GW, Fleige $\mathrm{H}$ et al (2016) Scheffer/ Schachtschabel soil science, 1st edn. Springer, Berlin

8. Bolan NS, Adriano DC, Kunhikrishnan A et al (2011) Dissolved organic matter: biogeochemistry, dynamics, and environmental significance in soils. In: Sparks DL (ed) Advances in agronomy. Academic Press, New York, pp 1-75

9. Bossuyt H, Denef K, Six J et al (2001) Influence of microbial populations and residue quality on aggregate stability. Appl Soil Ecol 16:195-208. https://doi.org/10.1016/S0929-1393(00)00116-5

10. Brimecombe MJ, De Leij FA, Lynch JM (2000) The effect of root exudates on rhizosphere microbial populations. In: Pinton $\mathrm{R}$, Varanini Z, Nannipieri P (eds) The rhizosphere. CRC Press, Boca Raton, pp 111-156

11. Buchmann C, Meyer M, Schaumann GE (2015) Characterization of wet aggregate stability of soils by H-NMR relaxometry. Magn Reson Chem 53:694-703. https://doi.org/10.1002/mrc.4147

12. Campbell CA, Biederbeck VO, Zentner RP, Lafond GP (1991) Effect of crop rotations and cultural practices on soil organic matter, microbial biomass and respiration in a thin Black Chernozem. Can J Soil Sci 71:363-376. https://doi.org/10.4141/cjss9 1-035

13. Cerli C, Celi L, Kalbitz K et al (2012) Separation of light and heavy organic matter fractions in soil-testing for proper density cutoff and dispersion level. Geoderma 170:403-416. https://doi. org/10.1016/j.geoderma.2011.10.009

14. Davidson EA, Janssens IA (2006) Temperature sensitivity of soil carbon decomposition and feedbacks to climate change. Nature 440:165-173. https://doi.org/10.1038/nature04514

15. Díaz-Hernández JL, Salmerón T (2012) Effects of a plastic cover on soil moisture change in a Mediterranean climatic regime. Soil Use Manag 28:596-605. https://doi.org/10.1111/sum.12000

16. Domagała-Świątkiewicz I, Siwek P (2018) Effects of plastic mulches and high tunnel raspberry production systems on soil physicochemical quality indicators. Int Agrophys 32:39-47. https://doi.org/10.1515/intag-2016-0088

17. Fernandez GE, Butler LM, Louws FJ (2001) Strawberry growth and development in an annual plasticulture system. HortScience 36:1219-1223. https://doi.org/10.21273/HORTSCI.36.7.1219
18. Frey SD, Drijber R, Smith H, Melillo J (2008) Microbial biomass, functional capacity, and community structure after 12 years of soil warming. Soil Biol Biochem 40:2904-2907. https://doi. org/10.1016/j.soilbio.2008.07.020

19. Gan Y, Siddique KHM, Turner NC et al (2013) Ridge-furrow mulching systems - an innovative technique for boosting crop productivity in semiarid rain-fed environments. In: Sparks DL (ed) Advances in agronomy. Academic Press, New York, pp 429-476

20. Harris D, Horwáth WR, van Kessel C (2001) Acid fumigation of soils to remove carbonates prior to total organic carbon or CARBON-13 isotopic analysis. Soil Sci Soc Am J 65:1853-1856. https ://doi.org/10.2136/sssaj2001.1853

21. Haynes RJ (2005) Labile organic matter fractions as central components of the quality of agricultural soils: an overview. Adv Agron 85:221-268. https://doi.org/10.1016/S0065 -2113(04)85005-3

22. Heißner A, Schmidt S, von Elsner B (2005) Comparison of plastic films with different optical properties for soil covering in horticulture: test under simulated environmental conditions. J Sci Food Agric 85:539-548. https://doi.org/10.1002/jsfa.1862

23. Huo L, Pang $\mathrm{H}$, Zhao $\mathrm{Y}$ et al (2017) Buried straw layer plus plastic mulching improves soil organic carbon fractions in an arid saline soil from Northwest China. Soil Tillage Res 165:286-293. https:// doi.org/10.1016/j.still.2016.09.006

24. IUSS Working Group WRB (2015) World reference base for soil resources 2014, update 2015. International soil classification system for naming soils and creating legends for soil maps. World soil resources reports no. 106. FAO, Rome

25. Jaeger $\mathrm{CH}$, Lindow SE, Miller W et al (1999) Mapping of sugar and amino acid availability in soil around roots with bacterial sensors of sucrose and tryptophan. Appl Environ Microbiol 65:2685-2690

26. Jiang X, Li XG (2015) Assessing the effects of plastic film fully mulched ridge-furrow on rainwater distribution in soil using dye tracer and simulated rainfall. Soil Tillage Res 152:67-73. https://doi.org/10.1016/j.still.2015.04.002

27. Joergensen RG, Brookes PC (1990) Ninhydrin-reactive nitrogen measurements of microbial biomass in $0.5 \mathrm{~m} \mathrm{~K}_{2} \mathrm{SO}_{4}$ soil extracts. Soil Biol Biochem 22:1023-1027. https://doi.org/10.1016/00380717(90)90027-W

28. Joergensen RG, Emmerling C (2006) Methods for evaluating human impact on soil microorganisms based on their activity, biomass, and diversity in agricultural soils. J Plant Nutr Soil Sci 169:295-309. https://doi.org/10.1002/jpln.200521941

29. Kaschuk G, Alberton O, Hungria M (2010) Three decades of soil microbial biomass studies in Brazilian ecosystems: lessons learned about soil quality and indications for improving sustainability. Soil Biol Biochem 42:1-13. https://doi.org/10.1016/j.soilb io.2009.08.020

30. Kasirajan S, Ngouajio M (2012) Polyethylene and biodegradable mulches for agricultural applications: a review. Agron Sustain Dev 32:501-529. https://doi.org/10.1007/s13593-011-0068-3

31. Khan AR, Chandra D, Quraishi S, Sinha RK (2000) Soil aeration under different soil surface conditions. J Agron Crop Sci 185:105-112. https://doi.org/10.1046/j.1439-037X.2000.00417 .x

32. Kindler R, Siemens JAN, Kaiser K et al (2011) Dissolved carbon leaching from soil is a crucial component of the net ecosystem carbon balance. Glob Change Biol 17:1167-1185. https://doi. org/10.1111/j.1365-2486.2010.02282.x

33. Kudeyarov VN, Demkin VA, Gilichinskii DA et al (2009) Global climate changes and the soil cover. Eurasian Soil Sci 42:953-966. https://doi.org/10.1134/S1064229309090014 
34. Kumar S, Dey P (2011) Effects of different mulches and irrigation methods on root growth, nutrient uptake, water-use efficiency and yield of strawberry. Sci Hortic 127:318-324. https://doi. org/10.1016/j.scienta.2010.10.023

35. Kurganova IN, De Gerenyu VL, Myakshina TN et al (2011) $\mathrm{CO}_{2}$ emission from soils of various ecosystems of the southern taiga zone: data analysis of continuous 12-year monitoring. Dokl Biol Sci. 436:56-58

36. Lal R (2006) Encyclopedia of soil science. CRC Press, New York

37. Lamont WJ (2005) Plastics: modifying the microclimate for the production of vegetable crops. HortTechnology 15:477-481. https://doi.org/10.21273/HORTTECH.3.1.35

38. Lamont WJ (1993) Plastic mulches for the production of vegetable crops. HortTechnology 3:35-39. https://doi.org/10.21273/ HORTTECH.15.3.0477

39. Li F-M, Song Q-H, Jjemba PK, Shi Y-C (2004) Dynamics of soil microbial biomass $C$ and soil fertility in cropland mulched with plastic film in a semiarid agro-ecosystem. Soil Biol Biochem 36:1893-1902. https://doi.org/10.1016/j.soilbio.2004.04.040

40. Li R, Hou X, Jia Z, Han Q (2016) Mulching materials improve soil properties and maize growth in the Northwestern Loess Plateau, China. Soil Res 54:708-718. https://doi.org/10.1071/SR15175

41. Li Y-S, Wu L-H, Zhao L-M et al (2007) Influence of continuous plastic film mulching on yield, water use efficiency and soil properties of rice fields under non-flooding condition. Soil Tillage Res 93:370-378. https://doi.org/10.1016/j.still.2006.05.010

42. Lieten $P$ (2005) Strawberry production in Central Europe. Int J Fruit Sci 5:91-105. https://doi.org/10.1300/J492v05n01_09

43. Liu C-A, Li F-R, Zhou L-M et al (2013) Effects of water management with plastic film in a semi-arid agricultural system on available soil carbon fractions. Eur J Soil Biol 57:9-12. https://doi. org/10.1016/j.ejsobi.2013.03.007

44. Luo S, Zhu L, Liu J et al (2015) Sensitivity of soil organic carbon stocks and fractions to soil surface mulching in semiarid farmland. Eur J Soil Biol 67:35-42. https://doi.org/10.1016/j.ejsob i.2015.01.004

45. Márquez C, Garcia V, Cambardella C et al (2004) Aggregate-size stability distribution and soil stability. Soil Sci Soc Am J 68:725735. https://doi.org/10.2136/sssaj2004.7250

46. Moore JM, Klose S, Tabatabai MA (2000) Soil microbial biomass carbon and nitrogen as affected by cropping systems. Biol Fertil Soils 31:200-210. https://doi.org/10.1007/s003740050646

47. Moreno MM, Moreno A (2008) Effect of different biodegradable and polyethylene mulches on soil properties and production in a tomato crop. Sci Hortic 116:256-263. https://doi.org/10.1016/j. scienta.2008.01.007

48. Muñoz K, Buchmann C, Meyer M et al (2017) Physicochemical and microbial soil quality indicators as affected by the agricultural management system in strawberry cultivation using straw or black polyethylene mulching. Appl Soil Ecol 113:36-44. https ://doi.org/10.1016/j.apsoil.2017.01.014

49. Ontl TA, Cambardella CA, Schulte LA, Kolka RK (2015) Factors influencing soil aggregation and particulate organic matter responses to bioenergy crops across a topographic gradient. Geoderma 255:1-11. https://doi.org/10.1016/j.geode rma.2015.04.016

50. Pietikåinen J, Pettersson M, Bååth E (2005) Comparison of temperature effects on soil respiration and bacterial and fungal growth rates. FEMS Microbiol Ecol 52:49-58. https://doi. org/10.1016/j.femsec.2004.10.002

51. Qin S-H, Cao L, Zhang J-L et al (2016) Soil nutrient availability and microbial properties of a potato field under ridge-furrow and plastic mulch. Arid Land Res Manag 30:181-192. https:// doi.org/10.1080/15324982.2015.1033066

52. Ramakrishna A, Tam HM, Wani SP, Long TD (2006) Effect of mulch on soil temperature, moisture, weed infestation and yield of groundnut in northern Vietnam. Field Crops Res 95:115-125. https://doi.org/10.1016/j.fcr.2005.01.030

53. Ruidisch M, Kettering J, Arnhold S, Huwe B (2013) Modeling water flow in a plastic mulched ridge cultivation system on hillslopes affected by South Korean summer monsoon. Agric Water Manag 116:204-217. https://doi.org/10.1016/j.agwat .2012.07.011

54. Schirmel J, Albert J, Kurtz MP, Muñoz K (2018) Plasticulture changes soil invertebrate assemblages of strawberry fields and decreases diversity and soil microbial activity. Appl Soil Ecol 124:379-393. https://doi.org/10.1016/j.apsoil.2017.11.025

55. Schmidt-Heydt M, Magan N, Geisen R (2008) Stress induction of mycotoxin biosynthesis genes by abiotic factors. FEMS Microbiol Lett 284:142-149. https://doi.org/10.111 1/j.1574-6968.2008.01182.x

56. Schonbeck MW, Evanylo GK (1998) Effects of mulches on soil properties and tomato production II. Plant-available nitrogen, organic matter input, and tilth-related properties. J Sustain Agr 13:83-100. https://doi.org/10.1300/J064v13n01_07

57. Smith J, Papendick R, Bezdicek D et al (1993) Soil organic matter dynamics and crop residue management. In: Metting FB Jr (ed) Soil microbial ecology: applications in agricultural and environmental management. Marcel Dekker, New York, pp 65-93

58. Steinmetz Z, Wollmann C, Schaefer M et al (2016) Plastic mulching in agriculture. Trading short-term agronomic benefits for long-term soil degradation? Sci Total Environ 550:690-705. https ://doi.org/10.1016/j.scitotenv.2016.01.153

59. Subrahmaniyan K, Kalaiselvan $P$, Balasubramanian TN, Zhou W (2006) Crop productivity and soil properties as affected by polyethylene film mulch and land configurations in groundnut (Arachis hypogaea L.). Arch Agron Soil Sci 52:79-103. https://doi. org/10.1080/03650340500421786

60. Tindall JA, Beverly RB, Radcliffe DE (1991) Mulch effect on soil properties and tomato growth using micro-irrigation. Agron J 83:1028-1034. https://doi.org/10.2134/agronj1991.0002196200 $8300060019 x$

61. Tisdall JM, Oades JM (1982) Organic matter and water-stable aggregates in soils. J Soil Sci 33:141-163. https://doi. org/10.1111/j.1365-2389.1982.tb01755.x

62. Vance ED, Brookes PC, Jenkinson DS (1987) An extraction method for measuring soil microbial biomass $C$. Soil Biol Biochem 19:703-707. https://doi.org/10.1016/0038-0717(87)90052 $-6$

63. von Lützow M, Kögel-Knabner I, Ekschmitt $\mathrm{K}$ et al (2006) Stabilization of organic matter in temperate soils: mechanisms and their relevance under different soil conditionsa review. Eur J Soil Sci 57:426-445. https://doi.org/10.111 1/j.1365-2389.2006.00809.x

64. von Lützow M, Kögel-Knabner I, Ekschmitt K et al (2007) SOM fractionation methods: relevance to functional pools and to stabilization mechanisms. Soil Biol Biochem 39:2183-2207. https ://doi.org/10.1016/j.soilbio.2007.03.007

65. Wang L, Li XG, Lv J et al (2017) Continuous plastic-film mulching increases soil aggregation but decreases soil $\mathrm{pH}$ in semiarid areas of China. Soil Tillage Res 167:46-53. https://doi. org/10.1016/j.still.2016.11.004

66. Wang YP, Li XG, Fu T et al (2016) Multi-site assessment of the effects of plastic-film mulch on the soil organic carbon balance in semiarid areas of China. Agric For Meteorol 228-229:42-51. https://doi.org/10.1016/j.agrformet.2016.06.016

67. Wang YP, Li XG, Hai L et al (2014) Film fully-mulched ridge-furrow cropping affects soil biochemical properties and maize nutrient uptake in a rainfed semi-arid environment. Soil Sci Plant Nutr 60:486-498. https://doi.org/10.1080/00380768.2014.909709

68. Wardle DA (1992) A comparative assessment of factors which influence microbial biomass carbon and nitrogen levels in soil. 
Biol Rev 67:321-358. https://doi.org/10.1111/j.1469-185X.1992. tb00728.x

69. Wardle DA, Parkinson D (1990) Interactions between microclimatic variables and the soil microbial biomass. Biol Fertil Soils 9:273-280

70. Xiukang W, Zhanbin L, Yingying X (2015) Effects of mulching and nitrogen on soil temperature, water content, nitrate-N content and maize yield in the Loess Plateau of China. Agric Water Manag 161:53-64. https://doi.org/10.1016/j.agwat.2015.07.019

71. Yin H, Xiao J, Li Y et al (2013) Warming effects on root morphological and physiological traits: the potential consequences on soil $\mathrm{C}$ dynamics as altered root exudation. Agric For Meteorol 180:287-296. https://doi.org/10.1016/j.agrformet.2013.06.016

72. Zhang F, Zhang W, Li M et al (2017) Does long-term plastic film mulching really decrease sequestration of organic carbon in soil in the Loess Plateau? Eur J Agron 89:53-60. https://doi. org/10.1016/j.eja.2017.06.007

73. Zhang GS, Hu XB, Zhang XX, Li J (2015) Effects of plastic mulch and crop rotation on soil physical properties in rain-fed vegetable production in the mid-Yunnan plateau, China. Soil Tillage Res 145:111-117. https://doi.org/10.1016/j.still.2014.09.010

74. Zhao Y, Zhai $X$, Wang Z et al (2018) Simulation of soil water and heat flow in ridge cultivation with plastic film mulching system on the Chinese Loess Plateau. Agric Water Manag 202:99-112. https://doi.org/10.1016/j.agwat.2018.02.017

75. Zhou L-M, Jin S-L, Liu C-A et al (2012) Ridge-furrow and plasticmulching tillage enhances maize-soil interactions: opportunities and challenges in a semiarid agroecosystem. Field Crops Res 126:181-188. https://doi.org/10.1016/j.fcr.2011.10.010

Publisher's Note Springer Nature remains neutral with regard to jurisdictional claims in published maps and institutional affiliations. 